\title{
Iodine Reaction of Poly(vinyl alcohol) Fractionated by Foaming
}

\author{
Kiyoshi Kikukawa, ${ }^{*}$ Shun-ichi Nozakura, and Shunsuke Murahashi \\ Department of Polymer Science, Faculty of Science, Osaka University, \\ Toyonaka, Osaka, 560, Japan.
}

(Received June 25, 1971)

\begin{abstract}
It has been confirmed that foam fractionation of an aqueous poly(vinyl alcohol)(PVA) solution produced PVAs with different reactivity in the PVA-iodine reaction, namely the color intensity decreased with increase in the fraction number. This result was found not only with a PVA derived from poly(vinyl acetate)(PVAc), but also with a specimen derived from cationically polymerized poly(vinyl trimethylsilyl ether)(poly(VOSi)). Particularly in the case of PVA obtained from PVAc (DP, 1652, and syndiotacticity, $50.0 \%$ in dyad), the variation of color intensity among the fractions cannot be explained by any one of the structural factors such as molecular weight, the 1,2-glycol structure, stereoregularity, and the carbonyl group in the main chain. Therefore another molecular structure, for example short branching, which will affect the PVA-iodine reaction and the foam fractionation, should be considered. The result also indicates the homogeneity of PVA from PVAc with respect to stereoregularity and the 1,2-glycol structure contents. In the case of PVA obtained from poly(VOSi)(DP, 1496 , and syndiotacticity, $37.5 \%$ in dyad), the fractionation with respect to stereoregularity has occurred; syndiotacticity of PVA contained in foam layers was higher than that in the residual solution. This result indicates that the PVA derived from poly(VOSi) consisted of stereoblock and/or a mixture of PVA of different tacticity.

KEY WORDS Poly(vinyl alcohol) / Foam Fractionation / Fractionation / PVA-Iodine Reaction / Stereoregularity / 1,2-Glycol Structure / Branching / Iodine /
\end{abstract}

Imai, et al., separated a poly(vinyl alcohol) (PVA) derived from radically polymerized poly (vinyl acetate) (PVAc) into fractions by foaming an aqueous solution. ${ }^{1}$ The fractions showed different reactivity in the PVA-iodine reaction though there was little difference in degree of polymerization and in the 1,2-glycol content. They suggested that PVA was fractionated according to stereoregularity. But there arises a question in considering the presence of a wide difference of stereoregularity among individual polymer molecules of a radical polymer.

It is known that even a minor change in molecular structure of PVA influences the properties of PVA. Factors, which may affect crystallinity and the PVA-iodine reaction, involve the 1,2glycal structure, the carbonyl group in the main chain, branching, and stereoregularity. Since the

* Present address: Department of Organic Synthesis, Faculty of Engineering, Kyushu University, Hakozaki, Fukuoka, 812, Japan. method of determination of stereoregularity was established, ${ }^{2}$ PVA samples with different stereoregularities have been prepared in order to study the effect of stereoregularity on properties of PVA. $^{3}$ The increase of isotacticity of PVA lowers. melting point, crystallinity, and color intensity of the PVA-iodine reaction. ${ }^{3-5}$ The increase of the 1,2-glycol structure also deteriorates the crystallinity ${ }^{4}$ and fades the color of the PVAiodine reaction. ${ }^{5}$ In addition, Shibatani, et al., have shown that a minor change in 1,2-glycol contents remarkably affects the PVA-iodine color reaction. ${ }^{6}$

This work was undertaken to investigate in detail the properties of PVA fractionated by foaming, and to elucidate the effect of the change in the molecular structure of PVA on the PVA -iodine reaction and the foam fractionation. Foam fractionation of PVA derived from cationically polymerized poly(vinyl trimethyl silyl ether) (poly(VOSi)) which was nearly atactic, was also 
investigated.

\section{EXPERIMENTAL}

\section{PVA Samples}

Sample A was a commercial PVA(Kuraray Co., Ltd.) which was derived from radically polymerized PVAc: degree of polymerization, 1652; residual acetate group, $0.23 \%$; sodium acetate, $0.2 \%$; syndiotacticity, $50.0 \%$ in dyad; the $1,2-$ glycol content, $2.12 \%$.

Sample B was prepared by methanolysis of a poly(VOSi) prepared from the cationic polymerization of VOSi. The polymerization procedure was as follows: a mixture of $200 \mathrm{ml}$ of $\mathrm{VOSi}$, $1000 \mathrm{ml}$ of methylene chloride, and $800 \mathrm{ml}$ of toluene was placed in a $2 l$ three-necked flask under a nitrogen atomosphere, the flask then being cooled to $-70^{\circ} \mathrm{C}$ in a Dry Ice-methanol bath. When ethylaluminum dichloride $(0.7 \mathrm{~m} l)$ was added slowly to the flask under stirring, the reaction temperature rose temporarily to $-50^{\circ} \mathrm{C}$, and then the solution was stirred for two hours at $-70^{\circ} \mathrm{C}$. The polymerization mixture was poured into a large amount of methanol. Methanolysis of the resulting polymer and precipitation of PVA occurred simultaneously. The PVA was washed several times with methanol by decantation and separated by filtration and dried under vacuum: yield, $52.0 \mathrm{~g}(91 \%)$; degree of polymerization, 1496; syndiotacticity, $37.5 \%$ in dyad; the 1,2-glycol content, $0.25 \%$.

\section{Foam Fractionation}

Sample A. A solution of $60 \mathrm{~g}$ of PVA and $3 l$ of water was placed in a $5 l$ wide-mouthed bottle. The bottle was shaken at a frequency of 68 cycles per minute; a foam layer was thus created. After being shaken for an appropriate period, the solution was allowed to stand for a certain time. In the course of this standing, part of the foam usually disintegrated and the remaining foam layer was taken out as a foam cake. The residual solution was usually cloudy, and there was a slight amount of precipitate at the bottom of the bottle. To obtain successive fractions, the cloudy solution was heated until it became completely clear and then the procedure involving shaking, standing, separation, and heating was repeated.
Sample B. Fractionation procedure was the same as the above except for the use of $40 \mathrm{~g}$ of PVA and $2 l$ of water.

\section{PVA-Iodine Color Reaction}

An aqueous PVA solution was mixed with a $\mathrm{KI}-\mathrm{I}_{2}$ solution at $6-3^{\circ} \mathrm{C}$ and kept at this temperature for $23 \mathrm{hr}$. The mixture was subjected to spectroscopic measurement at room temperature using a Hitachi spectrophotometer, EPS-3T.

$$
\begin{array}{cl}
\text { Sample A: } & {[\mathrm{PVA}]=15 \mathrm{mmol} / l,} \\
& {\left[\mathrm{I}_{2}\right]=1.25 \mathrm{mmol} / \mathrm{l},} \\
& {[\mathrm{KI}]=5 \mathrm{mmol} / \mathrm{l} .} \\
\text { Sample B: } & {[\mathrm{PVA}]=30 \mathrm{mmol} / l,} \\
& {\left[\mathrm{I}_{2}\right]=1.25 \mathrm{mmol} / l,} \\
& {[\mathrm{KI}]=5 \mathrm{mmol} / l .}
\end{array}
$$

\section{Characterization of PVA}

Degree of polymerization of PVA was calculated from viscosity of $1-\%$ aqueous PVA solution at $30^{\circ} \mathrm{C}$ according to the equation presented by Nakajima, et al. ${ }^{7}$

Dyad syndiotacticity of PVA was calculated from the absorbance ratio, $D_{916} / D_{849}$, of the IR spectra of PVA films, which was prepared from $1-\%$ aqueous solution and dried at $30^{\circ} \mathrm{C}$ in a silica gel desiccator, according to the following equation presented by us. ${ }^{2}$

$$
s(\text { dyad }) \%=72.4\left(D_{916} / D_{849}\right)^{0.43}
$$

The content of 1,2-glycol structure was determined by titrating the periodic acid consumption by PVA in accordance with the method of Harris, et al. ${ }^{8}$ In the case of sample $\mathrm{B}$, the content was also determined by measuring the degree of polymerization of PVA oxydized by periodic acid in accordance with the method of Flory. ${ }^{9}$

The carbonyl group in the main chain was measured by the UV spectra of aqueous PVA solutions. Absorption maxima at $240 \mathrm{~m} \mu$ and $280 \mathrm{~m} \mu$ were assigned to<smiles></smiles>

respectively. ${ }^{10}$

\section{RESULTS}

The results of foam fractionation of sample A and sample B are given in Tables I and II, respectively. Sample A produced stable foams 
Table I. Foam fractionation of sample A

\begin{tabular}{cccrc}
\hline \multirow{2}{*}{$\begin{array}{c}\text { Fraction } \\
\text { no. }\end{array}$} & \multirow{2}{*}{$\begin{array}{c}\text { Shaking } \\
\text { time, hr }\end{array}$} & $\begin{array}{c}\text { Standing } \\
\text { time, hr }\end{array}$ & \multicolumn{2}{c}{ Yield } \\
\cline { 4 - 5 } A 1 & 18 & 5 & 3.09 & 5.15 \\
A 2 & 18 & 5 & 3.77 & 6.28 \\
A 3 & 18 & 5 & 3.68 & 6.13 \\
A 4 & 21 & 24 & 3.72 & 6.20 \\
A 5 & 21 & 24 & 4.25 & 7.08 \\
A 6 & 21 & 24 & 3.72 & 6.20 \\
A 7 & 23 & 24 & 2.84 & 4.73 \\
A 8 & 21 & 24 & 3.58 & 5.97 \\
A 9 & 21 & 24 & 1.85 & 3.08 \\
A 10 & 21 & 24 & 2.26 & 3.77 \\
A 11 & 24 & 45 & 1.42 & 2.37 \\
A 12 & 24 & 45 & 1.52 & 2.53 \\
A 13 & 24 & 45 & 1.09 & 1.82 \\
A 14 & 24 & 45 & 0.85 & 1.42 \\
A 15 & 24 & 45 & 0.61 & 1.02 \\
A 16 & 24 & 45 & 0.57 & 0.95 \\
A 17 & 24 & 45 & 0.74 & 1.23 \\
A 18 & 24 & 45 & 0.56 & 0.93 \\
A-R & - & - & 16.90 & 28.17 \\
\hline Re & - & & &
\end{tabular}

a. Residual PVA in solution.

and thus gave a large number of fractions, whereas sample B produced less stable foams and most of the sample remained in solution. The change of the various properties of PVA according to the fractionation are given in Tables III and IV.

Figure 1 shows that the degree of polymerization of sample $A$ in each fraction was not con-

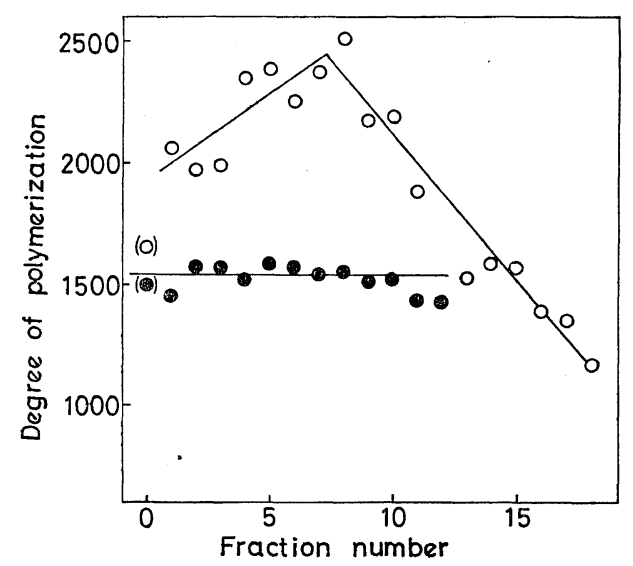

Figure 1. Degree of polymerization of fractions: O, sample A; e, sample $\mathbf{B}$.

Plots in parentheses represent the original PVA.
Table II. Foam fractionation of sample B

\begin{tabular}{ccccc}
\hline \multirow{2}{*}{$\begin{array}{c}\text { Fraction } \\
\text { no. }\end{array}$} & $\begin{array}{c}\text { Shaking } \\
\text { time, hr }\end{array}$ & $\begin{array}{c}\text { Standing } \\
\text { time, hr }\end{array}$ & \multicolumn{2}{c}{ Yield } \\
\cline { 4 - 5 } & & & $\mathrm{g}$ & $\%$ \\
\hline B 1 & 10 & 24 & 0.308 & 0.91 \\
B 2 & 20 & 48 & 1.030 & 2.56 \\
B 3 & 20 & 24 & 0.890 & 2.21 \\
B 4 & 20 & 24 & 0.599 & 1.48 \\
B 5 & 20 & 48 & 0.503 & 1.25 \\
B 6 & 20 & 24 & 0.320 & 0.79 \\
B 7 & 20 & 24 & 0.402 & 1.00 \\
B 8 & 20 & 24 & 0.308 & 0.76 \\
B 9 & 20 & 24 & 0.240 & 0.69 \\
B 10 & 20 & 48 & 0.111 & 0.27 \\
B 11 & 20 & 48 & 0.245 & 0.60 \\
B 12 & 20 & 48 & 0.126 & 0.31 \\
B-R & - & - & 35.24 & 88.0 \\
\hline
\end{tabular}

a Residual PVA in solution.

stant but increased slightly with an increase in the fraction number and then decreased. On the other hand, the degree of polymerization of sample B in each fraction was substantially constant.

There is little difference in the 1,2-glycol structure content of sample A (Table III) and sample B (Table IV) in each fraction and a systematic change was not found.

As may be seen in Figure 2, the stereoregularity of sample A in each fraction remained essentially unaltered within the experimental error and was the same as that of the original PVA. The syndiotacticity of sample B contained in the form layer was higher than that of the original PVA. Therefore sample B was separated according to syndiotacticity, but there was not systematic change of stereoregularity among fractions.

The aqueous solutions of sample $\mathrm{A}$ and sample B exhibited their absorption maxima at about $230 \mathrm{~m} \mu$ (sample A), $240 \mathrm{~m} \mu$ (sample B), and $280 \mathrm{~m} \mu$ (weak), which were assigned to<smiles>C=CC=CC(=O)[14CH]=CC=CC(C)=O</smiles>

respectively (Tables III and IV). ${ }^{10}$ The relationship between the absorbance at $230 \mathrm{~m} \mu(240 \mathrm{~m} \mu$ for sample B) and the fraction number is depicted in Figure 3; there is no clear-cut dependence of the absorbance on the fraction number though 
Iodine Reaction of PVA Fractionated by Foaming

Table III. Structure and properties of foam-fractionated sample A

\begin{tabular}{|c|c|c|c|c|c|c|}
\hline \multirow{2}{*}{$\begin{array}{c}\text { Fraction } \\
\text { no. }\end{array}$} & \multirow{2}{*}{$\mathrm{DP}$} & \multirow{2}{*}{$\begin{array}{c}\text { Syndiotac- } \\
\text { ticity, \% }\end{array}$} & \multirow{2}{*}{$\begin{array}{c}\text { 1,2-Glycol } \\
\text { mol\% }\end{array}$} & \multirow{2}{*}{$\begin{array}{l}\text { UV spectra } \\
d_{230}\end{array}$} & \multicolumn{2}{|c|}{$\mathrm{PVA}-\mathrm{I}_{2}$ reaction $^{\mathrm{b}}$} \\
\hline & & & & & $d_{\max }$ & $\lambda_{\max }, \mathrm{m} \mu$ \\
\hline $\mathrm{A} 0^{\mathrm{c}}$ & 1652 & 50.0 & 2.12 & - & 1.79 & 614 \\
\hline A 1 & 2060 & 53.0 & 2.14 & 2.5 & 3.23 & 614 \\
\hline A 2 & 1974 & 50.0 & - & 1.8 & 3.28 & 614 \\
\hline A 3 & 1991 & 50.0 & - & 2.7 & 3.07 & 614 \\
\hline A 4 & 2349 & 50.5 & 2.07 & 1.9 & 3.30 & 614 \\
\hline A 5 & 2384 & 51.0 & - & 1.3 & 3.20 & 614 \\
\hline A 6 & 2256 & 51.5 & - & 1.5 & 2.87 & 614 \\
\hline A 7 & 2371 & 52.0 & 2.03 & 0.77 & 2.70 & 614 \\
\hline A 8 & 2509 & $49 \cdot 0$ & - & 0.72 & 2.47 & 614 \\
\hline A 9 & 2173 & 51.0 & - & 0.94 & 2.13 & 614 \\
\hline A 10 & 2193 & 50.0 & 2.00 & 0.71 & 1.96 & 614 \\
\hline A 11 & 1879 & 49.0 & - & 0.83 & 1.51 & 614 \\
\hline A 12 & - & 49.5 & - & 0.86 & 1.07 & 614 \\
\hline A 13 & 1524 & 49.0 & 1.98 & 0.85 & 0.84 & 614 \\
\hline A 14 & 1583 & 49.5 & - & 1.4 & 0.79 & 614 \\
\hline A 15 & 1571 & 48.5 & - & 0.61 & 0.76 & 614 \\
\hline A 16 & 1490 & 49.0 & 2.05 & - & 0.44 & 614 \\
\hline A 17 & 1450 & 49.0 & - & 0.51 & 0.40 & 614 \\
\hline A 18 & 1168 & 48.5 & - & - & 0.31 & 614 \\
\hline$A-R^{d}$ & 743 & 48.5 & 2.13 & - & 0.06 & 614 \\
\hline
\end{tabular}

a Aqueous PVA solution (0.6\%); $\lambda \max 230 \mathrm{~m} \mu$.

b Reaction conditions; [PVA] $=15 \mathrm{mmol} / l ;\left[\mathrm{I}_{2}\right]=1.25 \mathrm{mmol} / l ;[\mathrm{KI}]=5 \mathrm{mmol} / l$ at $6-8^{\circ} \mathrm{C}$ for $23 \mathrm{hr}$.

c Original unfractionated PVA.

a Residual PVA in solution.

Table IV. Structure and properties of foam-fractionated sample B

\begin{tabular}{|c|c|c|c|c|c|c|}
\hline \multirow{2}{*}{$\begin{array}{c}\text { Fraction } \\
\text { no. }\end{array}$} & \multirow{2}{*}{$\mathrm{DP}$} & \multirow{2}{*}{$\begin{array}{c}\text { Syndiotac- } \\
\text { ticity, \% }\end{array}$} & \multirow{2}{*}{$\begin{array}{c}\text { 1,2-Glycol } \\
\text { mol\% }\end{array}$} & \multirow{2}{*}{ UV spectra ${ }^{\mathrm{a}}$} & \multicolumn{2}{|c|}{$\mathrm{PVA}-\mathrm{I}_{2}$ reaction $^{\mathrm{b}}$} \\
\hline & & & & & $d_{\max }$ & $\lambda_{\max }, \mathrm{m} \mu$ \\
\hline $\mathrm{B} 0^{\mathrm{c}}$ & 1496 & 37.5 & $0.25^{\mathrm{a}}, 0.35^{\mathrm{e}}$ & - & 0.216 & 596 \\
\hline B 1 & 1449 & 43.5 & - & 2.62 & 1.542 & 602 \\
\hline B 2 & 1577 & 44.0 & $0.14, \quad 0.1$ & - & 1.484 & 602 \\
\hline B 3 & 1578 & 41.5 & - & 1.10 & 1.411 & 605 \\
\hline B 4 & 1520 & 44.0 & - & 1.91 & 1.352 & 606 \\
\hline B 5 & 1585 & 41.5 &,$- \quad 0.50$ & 0.82 & 1.159 & 606 \\
\hline B 6 & 1572 & 42.5 & - & 0.98 & 1.081 & 606 \\
\hline B 7 & 1542 & 44.0 & - & 1.33 & 0.753 & 608 \\
\hline B 8 & 1554 & 42.5 & - & 0.84 & 0.735 & 606 \\
\hline B 9 & 1513 & 41.5 & - & 0.74 & 0.674 & 606 \\
\hline B 10 & 1522 & 42.0 & - & 0.96 & 0.953 & 605 \\
\hline B 11 & 1431 & 41.5 & - & 0.83 & 0.383 & 601 \\
\hline B 12 & 1424 & 41.0 & - & 0.80 & 0.413 & 597 \\
\hline $\mathrm{B}-\mathbf{R}^{\mathrm{d}}$ & 1490 & 38.0 & $0.40, \quad 0.58$ & - & 0.433 & 562 \\
\hline
\end{tabular}

a Aqueous PVA solution (0.6\%); $\lambda \max , 240 \mathrm{~m} \mu$.

b Reaction conditions; [PVA] $=30 \mathrm{mmol} / l ;\left[\mathrm{I}_{2}\right]=1.25 \mathrm{mmol} / l ;[\mathrm{KI}]=5 \mathrm{mmol} / l$ at $6-8^{\circ} \mathrm{C}$ for $23 \mathrm{hr}$.

c Original unfractionated PVA.

a Residual PVA in solution.

- Determined by the viscometric method.

$\mathrm{f}$ Determined by the periodate method. 


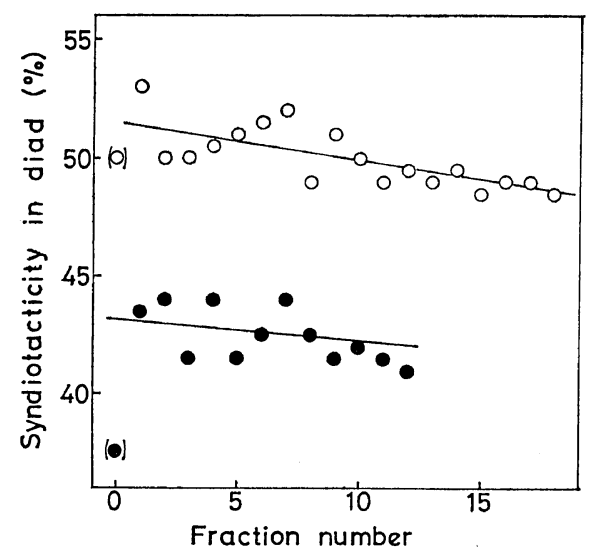

Figure 2. Stereoregularity of fractions: $\bigcirc$, sample A; 0 , sample B.

Plots in parentheses represent the original PVA.

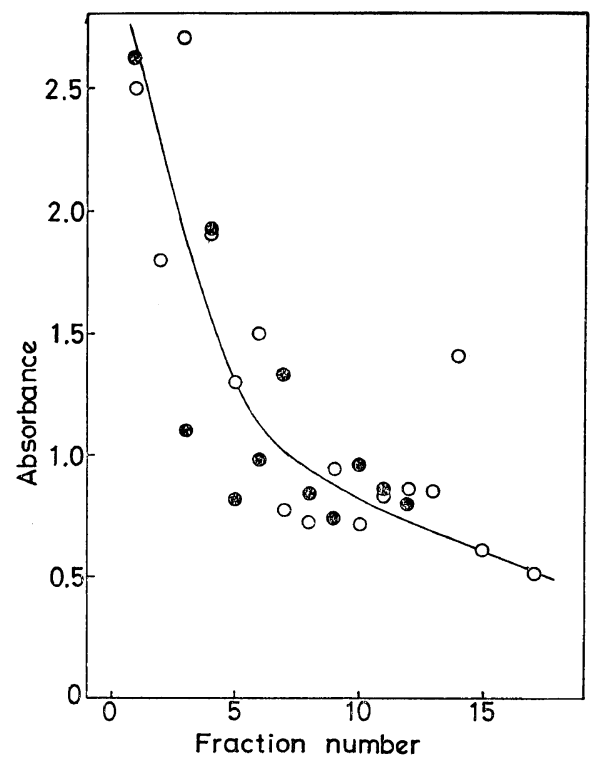

Figure 3. Absorbance at $230 \mathrm{~m} \mu$ (sample A) and $240 \mathrm{~m} \mu$ (sample B) of aqueous solution of fractions: $\bigcirc$, sample A; sample B; [PVA], $0.6 \%$ in water.

the early fractions tend to absorb more intensely than the later fractions.

The intensity of the PVA-iodine color reaction $\left(d_{\max }\right)$ of sample A and sample B is shown in Figure 4. Systematic changes of $d_{\max }$ of Sample A and Sample B in each fraction was clearly found, that is, as the fractionation progresses, $d_{\max }$ decreases remarkably. It is char-

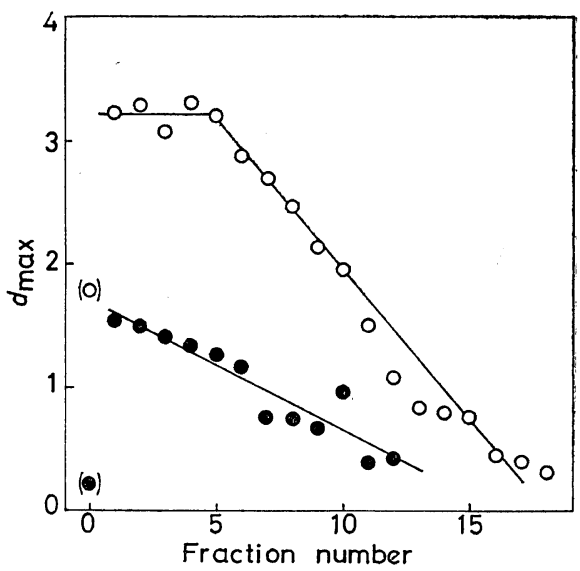

Figure 4. The iodine-color reaction of fractions: $\bigcirc$, sample A, [PVA], $15 \mathrm{mmol} / l,\left[\mathrm{I}_{2}\right], 1.25 \mathrm{mmol} / l$, [KI], $5 \mathrm{mmol} / l, 6 \sim 8^{\circ} \mathrm{C}, 23 \mathrm{hr}$; 8 , sample B, [PVA], $30 \mathrm{mmol} / l$.

Other conditions of sample B are the same as sample A.

Plots in parentheses represent the original PVA.

acteristic of Sample B that the absorption maxima varied with fraction number as shown in Table IV.

\section{DISCUSSION}

Foam fractionation in low-molecular-weight compounds takes advantage of absorption of surface-active agents on the interface and has found wide application. ${ }^{11}$ In the case of highmolecular-weight compounds such as protein, starch, and synthetic high polymer, the foam is stabilized by the formation of films of a gel-like substance. ${ }^{12}$ Viscosity of the solution also affects the stability of the foam. In the case of the solution of PVA, the formation of remarkably stable foam will suggest the gelation. Therefore the foam fractionation described here may be similar in principle to the mechanical denaturation of PVA solution reported by Go, et al..$^{13}$ The above discussion suggests the possibility of the fractionation of PVA according to the molecular structure, which influence the tendency of gelation, such as stereoregularity, the 1,2-glycol content, the carbonyl group, and branching.

As may be seen in Tables III, IV and Figure 4 , a characteristic result in the foam fractionation of a PVA solution was a decrease of the 
PVA-iodine color with an increase of fraction number. The PVA-iodine color reaction is strongly affected by molecular weight, stereoregularity, and the 1,2-glycol structure of PVA as reported previously. The color reaction is also reported to correspond to the degree of swelling of PVA, which probably reflects the crystallinity.

Figure 1 shows that the degree of polymerization of sample $\mathrm{A}$ is not constant but increases with an increase in the fraction number and then decreases, whereas that of sample $\mathbf{B}$ is essentially constant, that is, the fractionation did not occur with respect to molecular weight. Imai, et al., reported a linear relationship between the intensity of the PVA-iodine color and the degree of polymerization of fractionated PVA, $D_{620} \propto$ $D P{ }^{14} \quad$ A relationship between $d_{\max }$ corrected for molecular weight by the above equation $\left(d_{\max }\right.$ was used instead of $D_{620}$ ) and the fraction number is shown in Figure 5. The data of sample $\mathrm{B}$ in Figure 5 were converted to a concentration

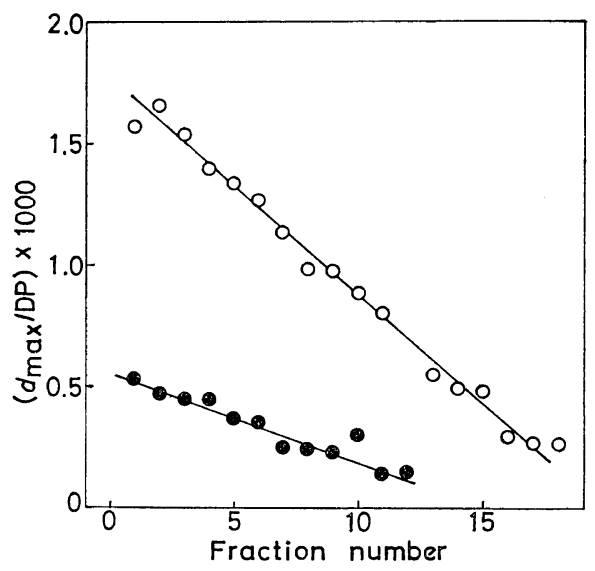

Figure 5. Corrected absorbance for the iodinecolor reaction of fractions: $\bigcirc$, sample A; (2) sample B.

The data of sample B were converted to $15 \mathrm{mmol} / \mathrm{l}$ PVA concentration.

of $15 \mathrm{mmol} / l$ of PVA in order to effect comparison directly with the data of sample A. The linear relationship between the corrected $d_{\max }$ and the fraction number also indicates that molecular weight is not a main factor of the change of $d_{\max }$.
The 1,2-glycol content of the fractions was almost constant, hence the fractionation with respect to the 1,2-glycol content did not occur, and the 1,2-glycol content cannot explain the decrease of the color. This result does not deny the possibility of foam fractionation according to the 1,2-glycol structure of PVA in general but represents the homogeneity of the PVA specimens.

Figure 2 shows that tacticity of the fractions of sample A was nearly equal to each other and to that of the original PVA. Since sample A is obtained from radically polymerized PVAc, the sequence of stereoregularity probably follows random distribution. Thus an appreciable difference should not be present concerning stereoregularity among individual polymer molecules and hence each of the fractions. The constancy of absorption maximum in the iodine color reaction also represents the homogeneity of the tacticity of sample A. ${ }^{5}$ Then, the decrease of $d_{\max }$ at sample $\mathrm{A}$ with the increase of fraction number cannot be explained by stereoregularity.

On the other hand, the syndiotacticity of the fractions of sample $B$ was higher than that of the original PVA, and the foam was unstable and the yield of foam was low compared with sample A though a difference in tacticity among the fractions was not found. These results suggest that a considerable syndiotacticity is necessary for producing a stable foam and that the foam fractionation with respect to stereoregularity has occurred for sample B. A large hypsochromic shift of absorption maximum of sample B with fraction numbers (Table IV) also shows the fractionation with respect to stereoregularity because an isotactic PVA shows the hypsochromic shift at the PVA-iodine color reaction. ${ }^{5}$ Sample $\mathrm{B}$ is probably heterogeneous with respect to stereoregularity. ${ }^{15}$ The high conversion and the elevation of temperature at the beginning of the polymerization may be one of the reasons for the production of the polymer molecules with different stereoregularity. In contrast, a successive change of tacticity was not found among the foam fractions as shown in Figure 2. The $d_{\max }$ of the fractions, however, decreased with the increase of the fraction number, though the difference in this case was smaller than that in 


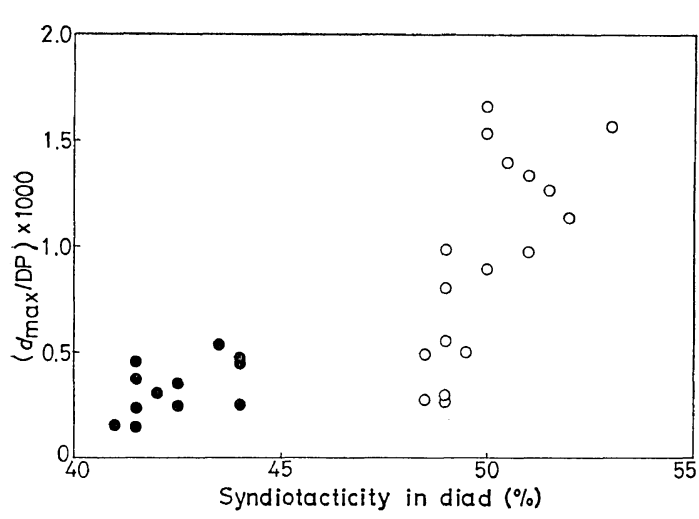

Figure 6. Relation between the iodine-color reaction and tacticity: $\bigcirc$, sample $\mathrm{A}$; 2 , sample $\mathrm{B}$.

the case of sample A (Figure 5). The $d_{\max }$ of sample $B$ of the residual solution was more intense than that of original PVA but these $d_{\max }$ should not be directly compared together because of the large difference of $\lambda_{\text {max }}$. Figure 6 shows the plots of the corrected $d_{\max }$ against syndiotacticity; these plots also show that the gradual decrease of $d_{\max }$ does not correlate with stereoregularity, namely, the stereoregularity is not a main factor governing the difference of the color reaction of PVA among the fractions.

Go, et al., reported that a mechanical stirring of an aqueous PVA solution yielded precipitates of PVA with different color intensity of the PVA-iodine reaction in spite of the same syndiotacticity as that of the original PVA. ${ }^{13}$ They suggest that the difference of sequence length of the syndiotactic part of each PVA is not the same. This suggestion, however, may not be reasonable in the present case because the PVA obtained by radical polymerization may consist of random sequence distribution of stereoregularity and the difference between polymer molecules is probably small.

The presence of the carbonyl group in the main chain is revealed by the absorption maximum at $230 \mathrm{~m} \mu$ (sample A), $240 \mathrm{~m} \mu$ (sample B), and $280 \mathrm{~m} \mu$. Figure 3 shows the plots of the absorbance of $230 \mathrm{~m} \mu$ and $240 \mathrm{~m} \mu$, which have been assigned to the $-\mathrm{C}-\mathrm{C}=\mathrm{C}$ structure, against<smiles>[CH]=O</smiles>

the fraction number. Roughly speaking the early fractions tend to show stronger absorptions.
These results disagree with the conventional information that the presence of abnormal structures disturbs the gelation and the PVA-iodine reaction. Thus the presence of carbonyl groups in the main chain is not a main factor in the change of PVA-iodine reaction.

Consequently none of molecular weight, stereoregularity, the 1,2-glycol structure, and the carbonyl group in the main chain may be a main factor governing the decrease of the color intensity of the PVA-iodine reaction with the increase of fraction number. Other factors should be considered.

One of the possible structural variations which will affect the cystallinity and PVA-iodine reaction is the branching of PVA, though the presence of branching has not been investigated in detail.

Imoto, et al., reported that long branching, which was prepared by the chain transfer on the backbone of PVA, was scarcely found. ${ }^{16}$ Murahashi, et al., have found that long branching on PVA does not affect the PVA-iodine reaction. ${ }^{17}$ This result is reasonable, for the presence of long branching probably shows little effect with respect to the microstructure of PVA because of the small number of branching points per polymer molecule.

Short branching has not been confirmed and its presence has been only speculated. The presence of short branching, however, seems reasonable because of a similar reactivity of the vinyl acetate radical to that of ethylene and from the consideration of the chain-transfer reaction of model compounds. ${ }^{18}$ Short branching may be produced by the back-biting mechanism. The high conversion will lead up to the low monomer concentration, and hence will produce different PVA molecules with respect to the frequency of short branching. In addition the gelation area of PVA surface film (about $10 \mathrm{~A}^{2} /$ monomer unit) is equal to or less than the calculated two-dimensional surface area of closed packing (about $12 \mathrm{~A}^{2} /$ monomer unit), and the polymer molecules should be brought close to each other at gelation. ${ }^{19}$ Therefore the presence of short branching probably disturbs both the PVA-iodine reaction and the formation of stable foam, the foam fractionation with respect to 
short branching being possible. At present, however, we must await the developement of a technique for the measurement of short branching.

In the case of sample B prepared from the cationic polymerization, the color intensity of the PVA-iodine reaction was weak owing to low syndiotacticity. It is noteworthy that the color intensity of PVA contained in foam layers decreased with the increase of fraction number similar to the case of sample A.

Acknowledgment. The authors are deeply indebted to Dr. M. Sumi for his many helpful suggestions and discussions in relation to this work, and to Mr. H. Iimuro for help in part of the measurements.

\section{REFERENCES}

1. K. Imai and M. Matsumoto, Bull. Chem. Soc. Japan, 36, 455 (1963).

2. S. Murahashi, S. Nozakura, M. Sumi, H. Yuki, and K. Hatada, J. Polym. Sci., Part B, 4, 65 (1966); Kobunshi Kagaku (Chem. High Polymers), 23, 605 (1966).

3. S. Murahashi, S. Nozakura. M. Sumi, and K. Matsumura, J. Polym. Sci., Part B, 4, 59 (1966); M. Sumi, K. Matsumura, R. Ohno, S. Nozakura, and S. Murahashi, Kobunshi Kagaku (Chem. High Polymers), 24, 606 (1967); S. Murahashi, S. Nozakura, and M. Sumi, J. Polym. Sci., Part B, 3, 245 (1965); S. Murahashi, S. Nozakura, M. Sumi, S. Fuji, and K. Matsumura, Kobunshi Kagaku (Chem. High Polymers),
23, 550 (1966).

4. K. Kikukawa, S. Nozakura, and S. Murahashi, Kobunshi Kagaku (Chem. High Polymers), 25, 19 (1968).

5. K. Kikukawa, S. Nozakura, and S. Murahashi, Polymer J., 2, 212 (1971).

6. K. Shibatani, M. Nakamura, and Y. Oyanagi, Kobunshi Kagaku (Chem. High Polymers), 26, 118 (1969).

7. A. Nakajima and K. Furudate, Kobunshi Kagaku (Chem. High Polymers), 6, 460 (1949).

8. H. E. Harris and J. G. Pritchard, J. Polym. Sci., Part A, 2, 3673 (1964).

9. J. P. Flory and F. S. Leuther, J. Polym. Sci., 3, 880 (1948).

10. D. G. Lloyd, J. Appl. Polym. Sci., 1, 70 (1959).

11. H. Kishimoto, Koroido to Kaimenkasseizai, 2, 494 (1961).

12. T. Sasaki, Kogyo Kagaku Zasshi (J. Chem. Soc. Japan, Ind. Chem. Sect.), 58, 809 (1955).

13. K. Nakamura, S. Matsuzawa, and Y. Go, Kobunshi Kagaku (Chem. High Polymers), 25, 577 (1968).

14. K. Imai and M. Matsumoto, J. Polym. Sci., 55, 335 (1961).

15. M. Sumi, S. Nozakura, and S. Murahashi, Kobunshi Kagaku (Chem. High Polymers), 24, 424 (1967).

16. S. Imoto, J. Ukida, and T. Kominami, ibid, 25, 101 (1957).

17. Y. Morishima, S. Nozakura, and S. Murahashi, to be published.

18. J. T. Clarke, R. O. Howard, and W. H. Stockmayer, Makromol. Chem., 44-46, 427 (1961). 